will strike the initiated reader as very eccentric; and I do not think it will help the beginner. The index of the book also seems to have its eccentricities. If one looks up "charge density" for example, one gets referred to two pages on neither of which is the concept defined or anything other than incidentally mentioned. One does not get referred to the section on p303, which has charge density in its heading, which is perhaps just as well because the section contains no mention at all of the idea.

The book cannot therefore be recommended unreservedly as an introduction to the field but it is nevertheless a book that repays careful reading and should be useful to those teaching advanced undergraduate and graduates in the subject, if only because there is not really another book in this area.

Electron Correlation consists of just two chapters, one entitled "First Order CI and VB methods" and the other (about 200 pages) "The Correlation Problem". Again, the emphasis is on diatomics but polyatomics get a better look in than in the Introduction. The underlying and unifying theme of the book seems to be designing wave functions for molecules which correctly describe their dissociation into fragments. In the first chapter the author takes a rather eclectic view of $\mathbf{C I}$ and $\mathrm{VB}$, and the reader looking for detailed accounts of the current state of the art in these methods will be disappointed. In fact most of the chapter is devoted to a discussion of symmetry principles, of a particular multi-configuration SCF method and of an introduction to the theory of separated electron pairs. The second chapter is devoted almost

\section{Ice Age, \\ ancient and modern}

The Ice Age: Past and Present. By Brian S. John. Pp. 254. (Collins: London, 1977.) $£ 4.95$.

ADDING to the rapidly expanding recent literature on glaciers, Ice Ages and such topics, Brian John has produced a useful non-technical volume that is designed to appeal to "the person who knows very little about ice and glaciers and even less about the Ice Age". In 235 pages it covers a great deal of ground, from how glacier ice is formed to its effects on the Earth's surface, from ancient Ice Ages to speculative comments on future climatic change. Inevitably the treatment becomes somewhat superficial in places, as when the botany of the Ice Age is surveyed in just 12 pages; but on the whole it entirely to pair theories culminating in an account of the coupled pair approximation treated in a manner equivalent to Cizek's treatment. After a short discussion of the requirements necessary to obtain chemical accuracy using such methods the chapter ends with a brief account of putting $r_{12}$ explicitly into the wave function particularly by the trans-correlated method.

Once more there are lots of good things in this book. There is a splendid account of natural spin-orbitals and the convergence of the $\mathrm{CI}$ expansion, and of the difficulties in iterative pseudonatural orbital approaches. There is a very clear and precise account of the deficiencies inherent in particular classes of wave functions constructed from strongly orthogonal groups. Indeed, the whole account of development of pair theories is clear, coherent and precise, and extremely well illustrated by results from actual calculations.

Again it does seem to lack references to more contemporary work: obvious omissions are the work of Meyer and that of Ahlrichs and his group in the pair function field. One would also expect to see more references to recent work in the CI and VB approaches. The result is that the book must strike the informed reader as a somewhat unbalanced account of the field.

The reviewer's reservations here are, however, only minor. Electron Correlation is a book that many practising quantum chemists will surely want to own.

\section{B. T. Sutcliffe}

B. T. Sutcliffe is Senior Lecturer in Chemistry at the University of York, UK.

succeeds very well in dealing with such a huge canvas. Moreover, it is a soundly based book: on geomorphological and geological aspects, John knows his stuff, and therefore unlike many popular or semi-popular accounts, the text is reliable and up-to-date.

The arrangement of material is clear and logical. The first half of the book looks at the nature and origins of glaciers, their effects on landforms through erosion and deposition, the landscapes associated with both continental and alpine types of glaciation, and the work of glacial meltwater in washing out and transporting debris away from the edge of the ice. There follow short chapters on ice in a periglacial environment, touching briefly on permafrost, frost weathering, patterned ground, pingos and other ground-ice features, and on sea ice, dealing with ice shelves, pack ice and icebergs.

The second half of the book deals mainly with Ice Ages. Sensibly, for this type of book, John begins with the recent historical past, discussing the effects and significance of the "Little Ice Age", before delving further into the past to consider the Pleistocene period and then the pre-Pleistocene glaciations, as well as the innumerable theories of the causes of Ice Ages. There is an outline of the effects of glaciation on land and sealevels; a minor criticism here is that non-glacial causes of changes in level tend to be ignored so that one gets the erroneous impression, for instance, that the sinking of the North Sea basin is somehow bound up with glaciation. Three chapters provide brief summaries of Ice Age plants, animals and man, and the book concludes with a discussion of what the future may hold in store-when will the present interglacial come to an end, how will it end, and what impact is man having on the world's glaciers, intentionally or unintentionally?

Throughout, John tries to write in a simple non-technical style. On the whole he probably succeeds in making the subject matter intelligible to the non-specialist, but often at the risk of over-simplification. At times, however, he lets his imagination run away with him. Such statements as "You don't have to ask an Eskimo whether we are living in the middle of an Ice Age", or "Like the Irish navvies of Victorian times, the most active glaciers tend to be the most efficient, and where they have plenty of excess energy they achieve prodigious feats of erosion and transportation", are probably acceptable in a book of this sort, but some other passages draw rather far-fetched similes. Did he really have to write that "Unstable glaciers cannot find relief from the stresses of life by weeping or getting drunk", or that "Pingos prefer to live in groups ...." (they are described as "lovable creatures" because they tend to cluster together)?

The book is well produced with few errors. An amusing slip is 'subsidising' instead of 'subsiding' on p230. The 32 half-tone plates are mostly of high quality (the ERTS imagery of Skeidarársandur is an exception), and the line-drawings are clear. The latter, oddly, are not numbered and not specifically referred to in the text. There is a short list of books for further reading, and an index. At $£ 4.95$, the book represents reasonable value for money; it ought to attract the non-specialist reader and it will certainly stimulate the intelligent sixth-former (advanced school) student to find out more about ice and Ice Ages.

Clifford Embleton

Clifford Embleton is Reader in Geography at King's College, University of London, $U K$. 